\title{
Kidney Cancer pN1 TNM Finding v7
}

National Cancer Institute

\section{Source}

National Cancer Institute. Kidney Cancer pN1 TNM Finding v7. NCI Thesaurus. Code C89295.

Kidney cancer with metastasis in regional lymph node(s). (from AJCC 7th Ed.) 